\title{
A IMAGEM ILUSTRATIVA DO TEXTO LITERÁRIO NO LIVRO DIDÁTICO ADAPTADO EM LIBRAS: ANÁLISE DA APROPRIAÇÃO DO ALUNO SURDO' ${ }^{1}$
}

\section{THE ILLUSTRATIVE IMAGE OF THE LITERARY TEXT IN THE TEXTBOOK ADAPTED IN LIBRAS: ANALYSIS OF THE APPROPRIATION OF THE DEAF STUDENT}

https://doi.org/10.46551/2179679320200002

Dayse Garcia Miranda

Universidade Federal de Ouro Preto- UFOP

daymgarcia@hotmail.com iD 1 ttps://orcid.org/0000-0002-7284-1867

\begin{abstract}
RESUMO: O artigo analisa a aplicação, a um aluno surdo, de uma unidade de livro didático de Língua Portuguesa adaptado em Libras cujas questões norteiam o ensino e a aprendizagem do português como segunda língua e discute a imagem ilustrativa como recurso de linguagem auxiliar para a compreensão do texto literário, bem como suas diversas possibilidades de leitura e apreensão de significado. Pela pesquisa de metodologia de cunho etnográfico, identificam-se entraves durante as atividades, como a ausência de alinhamento do significado da imagem com o texto literário e o pouco acesso à compreensão da leitura por meio da Libras. Conclui que o livro didático adaptado em Libras não promoveu condições ideais para a criança surda aprender o português como segunda língua.
\end{abstract}

PALAVRAS-CHAVE: Livro didático adaptado; Libras; Língua Portuguesa; segunda língua.

ABSTRACT: The article analyzes the application, to a deaf student, of a Portuguese Language textbook unit adapted in Libras (Brazilian Sign Language) whose questions guide the teaching and learning of Portuguese as a second language and discusses the illustrative image as an auxiliary language resource for understanding the literary text, as well as its diverse possibilities of reading and apprehension of meaning. By researching an ethnographic methodology, obstacles are identified during activities, such as the lack of alignment of the meaning of the image with the literary text and little access to understanding reading through Libras. It concludes that the textbook adapted in Libras did not promote ideal conditions for the deaf child to learn portuguese as a second language.

KEYWORDS: Adapted textbook; Libras; Portuguese; second language.

\section{Introdução}

\footnotetext{
${ }^{1}$ Recorte da pesquisa de doutorado "A multimodalidade no ensino de Língua Portuguesa como segunda língua para surdos: análise do uso do livro didático adaptado em Libras", defendida no CEFET-MG, em dez.2019.
} 
O livro didático (LD), objeto comum dentro da escola, ocupa um lugar significativo de importante instrumento pedagógico. Geralmente, o LD é um material impresso elaborado por especialistas de diferentes áreas - composto por textos, sistematizações, exemplos e exercícios - que auxilia o professor na dinâmica da sala de aula. Com o avanço da tecnologia, o LD vem sendo enriquecido por componentes midiáticos e atualmente se encontra também em versões digitais, que podem ser uma simples digitalização da página impressa ou contar com a inclusão de animações, links e/ou CD-ROMs.

Segundo Renato Caixeta da Silva, "o LD, como outros gêneros, tem caráter dinâmico, pois está sempre sujeito a alterações"², em consonância com as representações sociais que advogam no tempo, no espaço e nas políticas públicas. Essas mudanças permitiram a concepção de materiais didáticos (MDs) adaptados em Libras, e o LD assim adaptado se estrutura pela tradução da língua portuguesa (LP) escrita para a língua de sinais (LS), registrada em vídeos disponíveis em CD-ROM. A tecnologia digital abre mais possibilidades para os alunos surdos, mas é preciso manter-se alerta e verificar até onde esse recurso está voltado para o panorama da surdez.

Apoio-me em Vilson José Leffa para afirmar que o MD é uma ferramenta útil para criar condições de aprendizagem ${ }^{3}$. No caso da surdez, a LS é a primeira língua e a LP é considerada a segunda (L2) tendo seu uso na modalidade escrita. Fica evidente, então, que, nos MDs adaptados em Libras, as duas modalidades (LP/LS) estão presentes e se destinam aos fins didáticos.

A possibilidade de dispor de recursos visuais (LS) nos MDs facilita a inserção e favorece os alunos surdos. Essa concepção, em particular, a presença de várias linguagens, possibilita nova visão textual, isto é, aspectos multimodais representam diferentes modos discursivos. Sendo assim, é necessário indagar como funcionam os diversos modos em texto multimodal, como eles interagem e como cada um significa em um texto literário. Com relação à surdez, as questões não dizem somente das adaptações, mas dos elementos linguísticos e discursivos e de como podem contribuir no aprendizado de uma L2.

\footnotetext{
${ }^{2}$ SILVA, 2015, p. 39.

${ }^{3}$ LEFFA, 2008, p.11.
} 


\section{Revista Araticum}

Programa de Pós-graduação em Letras/Estudos Literários da Unimontes v. 21, n.1, 2020. ISSN: 2179-6793

Neste artigo, busco, portanto, refletir quanto ao uso ${ }^{4}$ e à apropriação ${ }^{5}$ do LD adaptado em Libras por um aluno surdo na sala de atendimento educacional especializado ( $A E E$ ), série inicial do ensino fundamental de uma escola da rede municipal de ensino de Belo Horizonte, e analisar uma atividade didática sobre um texto literário do LD de ensino de LP adaptado em Libras ensino de LP como L2 - a fim de discutir a importância do uso da imagem ilustrativa como recurso de linguagem para a compreensão do texto e suas diversas possibilidades de leitura e apreensão de significado.

\section{A imagem como recurso para o ensino de L2}

A discussão quanto ao letramento visual para crianças surdas é recente e centrada no ensino de LP como L2. Até então, o uso de imagens se relacionava e, de certo modo, era dependente do contexto verbal, constatando-se que as figuras são polissêmicas e abertas a uma variedade de possíveis significados, isto é, o significado visual é indefinido, é uma cadeia flutuante de significados. Para chegar a uma definição, a linguagem deve vir ao resgate.

A imagem está sob o ponto de vista da significação, e não da emoção ou do prazer estético: elas suscitam significados, ou seja, interpretações. Para Matine Joly, um signo é um signo apenas quando exprime ideias e suscita uma atitude interpretativa no espírito daquele ou daqueles que o recebem ${ }^{6}$. A imagem, mensagem bastante complexa, produz sentido na interação com o texto a partir da observação de forma mais sistemática, o que ajuda a compreender melhor o texto multimodal.

Se a imagem é entendida como "representação", assim é entendida como "signo". No LD, a imagem ilustrativa pode se tornar perigosa tanto por excesso como por falta de semelhança. Demasiada semelhança provocaria confusão entre imagem e sentido. Semelhança insuficiente causaria perturbadora e inútil ilegibilidade, visto que a imagem é:

[...] uma mensagem visual composta de diferentes tipos de signos

[...] um instrumento de expressão e de comunicação. Quer ela

\footnotetext{
${ }^{4}$ Para o artigo, essa palavra pode ser compreendida como a ação de manipular, ter o domínio do instrumento.

${ }^{5}$ Para o artigo, essa palavra pode ser compreendida como a ação de tomar para si, apoderar do aprendizado.

${ }^{6}$ JOLY, 2006, p.30.
} 
seja expressiva ou comunicativa, podemos admitir que uma imagem constitui sempre uma mensagem para o outro, mesmo quando este outro é o próprio autor da mensagem. É por isso que uma das precauções necessárias a tomar para melhor compreender uma mensagem visual é procurar para quem ela foi produzida ${ }^{7}$.

As imagens ilustrativas podem enriquecer a atividade de escrita em atividades que contenham textos multimodais se o aprendiz for provocado para olhar além do conteúdo. Pesquisadores como Marlon Kuntze, Debbie Golos e Charlotte Enns, em seus estudos, comprovam que os modos visuais são elementos naturais que auxiliam as crianças surdas, independentemente da diversidade auditiva, a alcançar maior sucesso na escrita da L2. A imagem, a Libras e a escrita representam diferentes modos discursivos que se complementam e auxiliam na compreensão e execução do exercício. Assim, para os alunos surdos, deve-se considerar que a relação com a imagem e o texto multimodal sempre estará numa relação visual ${ }^{8}$.

\section{Contexto e procedimentos da investigação}

Para este artigo, trato da aplicação de uma unidade didática em sala de recurso/AEE em escola inclusiva e bilíngue da rede municipal de Belo Horizonte, a um aluno surdo, de nove anos, matriculado em classe bilíngue do $5^{\circ}$ ano (multisseriada), no turno da manhã. Nessa sala, o aluno é atendido pelo professor de LP e por uma instrutora surda, que Ihe ensina Libras.

A observação ocorreu durante as aulas de LP e a coleta dos dados aconteceu durante a aplicação dessa unidade didática (UD), dentro de um cronograma estabelecido pelo professor. A unidade aplicada também foi indicada pelo regente, no caso, LD de ensino de LP da coleção Porta Aberta ${ }^{9}$. O professor participante elege a Libras como a língua base na interação com os alunos surdos. A coleta durou 45 dias, com frequência de duas vezes por semana. A cada visita, filmava 90 minutos de atendimento, levando a um total de 20 horas/aula filmadas.

Os dados coletados serão apresentados em um mapa de eventos

\footnotetext{
${ }^{7} \mathrm{JOLY}, 2006$, p. 61.

${ }^{8}$ KUNTZE, GOLOS \& ENNS, 2014, passin.

${ }^{9}$ Editora FTD, 5ำ ano, unidade 3, 2011.
} 
selecionado para dar visibilidade ao processo de interação durante a aplicação da referida UD do LD adaptado em Libras. Estabeleci alguns critérios a partir das análises da transcrição das filmagens registradas e dos dados registrados no diário de campo, a saber, pelos seguintes indicativos, organizados em colunas: Números - orientação dos diálogos; Unidade didática - descrição da unidade; Tradução - transcrição dos aspectos envolvidos na tradução do CD; Professor descrição das ações do professor; Aluno - descrição das ações do aluno; e Contextualização - descrição dos acontecimentos envolvidos no uso e na apropriação do LD.

Assim, procuro exemplificar a organização de um mapa da paisagem semiótica $^{10}$. Por meio de sua análise, temos uma ideia das ações adotadas pelos envolvidos para a compreensão da tarefa solicitada no LD. Com isso, pela transcrição em colunas, objetivo retratar a atividade e ações do aluno e do professor, bem como seus efeitos na aprendizagem da L2.

Outro procedimento adotado na pesquisa diz respeito à transcrição da Libras para a LP e aos diferentes recursos linguísticos utilizados pelos participantes. A Libras serviu como mediadora do processo de ensino e aprendizagem entre professor e aluno, e a LP escrita esteve presente no registro impresso e na tela digital.

Assim, escolhi um sistema de notação em palavras representadas por meio de glosas como forma de transcrever a LS para a LP. Para a transcrição dos eventos ocorridos durante a interação, orientei-me com base nas convenções de Giselli Maria da Silva ${ }^{11}$, que se utilizam de um sistema com algumas adaptações apropriadas à LS: as palavras escritas em LP com letras maiúsculas buscam representar o conceito expresso pelo sinal; quando é necessário duas ou mais palavras para expressar o conceito, estas são ligadas por hífen; palavras expressas em datilologia são registradas em letras maiúsculas separadas por hífen; verbos são representados no infinitivo, mesmo em casos de flexão; numerais indicam as pessoas do discurso; expressões não manuais são indicadas após a palavra/expressão, entre $<>$ e seguidos da pontuação pertinente; e demais comentários são indicados entre colchetes. Ainda, os

\footnotetext{
${ }^{10}$ Tomando a linguagem como prática social e a sala de aula, no caso, como paisagem semiótica.

${ }^{11}$ SILVA, 2018, p. 15.
} 
intervalos e as pausas curtas, mas significativas, estão marcados por dois pontos finais (..) e, as pausas longas, por reticências duplas (... ...); o uso de classificadores está indicado por $\mathrm{CL}$ junto à palavra; e as expressões corporais ou faciais que constituem os sinais são marcadas pelos caracteres ---?--- para interrogação, ---!--- para exclamação, ---ñ--- para negação e ---s--- para afirmação ou palavras que remetam a ela, tais como felicidade, tristeza, dúvida etc.

É necessário considerar que, ao se utilizar esse sistema de transcrição, alguns aspectos não verbais da LS não serão transcritos em sua íntegra, e, para esclarecer o uso e o efeito de um ou outro sinal, serão acrescidas informações que permitam ao leitor um melhor entendimento das interações dos participantes e compreensão das tarefas determinadas pelo LD.

\section{Estruturação e definição do evento analisado}

Para o artigo, reflito apenas sobre a atividade de "Preparação para a leitura", que trata do uso da imagem ilustrativa como elemento de oferta de conhecimentos prévios à leitura. A proposta da atividade é fomentar esse conhecimento para, então, chegar à excelência na leitura e à leitura do texto base.

Toda e qualquer unidade didática de um LDLP tem um texto base, e é a partir deste que todas as atividades são formuladas. A história "Como se fosse dinheiro", de Ruth Rocha, propõe a elaboração do conceito de dinheiro a partir da uma história que narra sobre o vendedor da cantina de uma escola que devolve o troco em balas em vez de moedas. O garoto protagonista, por sua vez, lança mão de outros objetos em detrimento do dinheiro em espécie, respondendo ao ato de substituição pecuniária.

Durante a preparação para a leitura literária, o uso da ilustração como recurso de linguagem foi o evento selecionado para a análise da ocorrência das interações de aprendizado de LP entre os participantes e o LD adaptado, com o objetivo de refletir sobre a importância dos aspectos visuais: como o uso da imagem ilustrativa pode ofertar informações contrárias à compreensão do texto; como o professor conduz a compreensão da imagem; a disponibilidade da LS na "janela de tradução" como contribuição ou não para o entendimento da proposta 
didática.

Para a teoria da semiótica social, a imagem não é uma simples configuração estética. Ela suscita ideias, produz sentido e é entendida como uma representação, assim entendida por signo. Para Vera Lúcia de Carvalho Selvatici, nos estudos de ensino de língua estrangeira, há apontamentos de que as imagens podem enriquecer a atividade escrita, embora se constate que muitas vezes não se adequam ao contexto do texto estudado ${ }^{12}$. Para os estudos surdos, de acordo com Tatiana Bolívar Lebedeff, a imagem pode ser considerada uma pista textual ${ }^{13}$, assim, a imagem é um texto, segundo Gunther Kress e Theo van Leeuwen, lido e compreendido por um processo de leitura ${ }^{14}$.

Busco, assim, mostrar como as línguas (LS/LP) estão sendo usadas, com quem os envolvidos estão interagindo durante a atividade e quais foram os comentários feitos pelo professor e pelo aluno. É importante considerar que todo texto (escrito ou em sinais) é um texto multimodal. Dessa forma, utilizam-se diferentes modos para comunicar significados: "os significados são expressos de maneiras distintas via modos diferentes dependendo da inserção do ser humano na cultura a que pertence, e dos recursos tecnológicos disponíveis" ${ }^{15}$.

Reforça-se que diferentes modos de uso de linguagem podem complementar informações e alcançar o objetivo da tarefa comunicativa. Com isso, cada modo tem sua potencialidade específica de representação e de comunicação e podem estar reunidos num mesmo objeto multimodal, aqui, no LD adaptado em Libras. Entretanto, os recursos tecnológicos tornam possível a interação dos diferentes modos, mas não obrigatoriamente os diferentes modos produzem diferentes modos de significar.

Partindo do princípio de que a imagem é uma representação textual, temos, no evento do Quadro 1, "Preparação para leitura", ações que encenam como o professor, a partir das orientações da atividade, busca significar a ilustração para o entendimento do texto:

\footnotetext{
${ }^{12}$ SELVATICI, 2015, p.121.

${ }^{13}$ LEBEDEFF, 2010, p.182.

14 KRESS; LEEUWEN, 2006, passim.

${ }^{15}$ SILVA, 2019, p. 67.
} 


\section{Revista Araticum}

Programa de Pós-graduação em Letras/Estudos Literários da Unimontes v. 21, n.1, 2020. ISSN: 2179-6793

QUADRO 1 - Recurso da Imagem (sala AEE)

(continua)

\begin{tabular}{|c|c|c|c|c|c|}
\hline \multicolumn{4}{|c|}{ QUADRU 1} & \multicolumn{2}{|c|}{ (continua) } \\
\hline $\mathrm{N}$ & Atividade didática & Tradução & Professor - ações e diálogos & Alunos - ações e diálogos & Contextualização \\
\hline 1 & $\begin{array}{l}\text { LDLP coleção Porta Aberta, } \\
\text { 5ªno, p. } 49 .\end{array}$ & & $\begin{array}{l}\text { [aponta o dedo indicador } \\
\text { para o menino da imagem] }\end{array}$ & & $\begin{array}{l}\text { Sala de aula AEE. } \\
\text { Iniciando atividade do } \\
\text { LDP. }\end{array}$ \\
\hline 2 & & & & [olha para a imagem] & \\
\hline 3 & & & LEVAR <QUE>---?--- & & \\
\hline 4 & & & & OVELHA & \\
\hline 5 & & & $\begin{array}{c}\text { [professor aponta para o } \\
\text { animal] }\end{array}$ & & \\
\hline 6 & & & PARECER <QUE> - --?--- & & \\
\hline 7 & & & & LER ---?--- & \\
\hline 8 & & & $\begin{array}{c}\text { [professor faz um círculo, } \\
\text { com o dedo indicador, na } \\
\text { imagem] }\end{array}$ & & $\begin{array}{c}\text { Professor busca a } \\
\text { imagem como auxílio } \\
\text { para preparar a leitura. }\end{array}$ \\
\hline 9 & & & & $\begin{array}{c}\text { [gira a cadeira e olha para } \\
\text { tela] }\end{array}$ & \\
\hline 10 & & & $<$ OLHAR> & & $\begin{array}{c}\text { Pede o aluno para olhar } \\
\text { para a tela. }\end{array}$ \\
\hline 11 & & & $<$ LEVAR $>\ldots$ & & \\
\hline
\end{tabular}




\section{Revista Araticum}

Programa de Pós-graduação em Letras/Estudos Literários da Unimontes v. 21, n.1, 2020. ISSN: 2179-6793

\begin{tabular}{|c|c|c|c|c|c|}
\hline $\mathrm{N}$ & Atividade didática & Tradução & Professor - ações e diálogos & Alunos - ações e diálogos & Contextualização \\
\hline & & & PASSEAR ---?--- & & \\
\hline 12 & & & & $<\mathrm{V}-\mathrm{l}>$ & \\
\hline 13 & & & <QUE> ---?--- & & $\begin{array}{l}\text { O professor levanta os } \\
\text { ombros e as mãos. }\end{array}$ \\
\hline 14 & & & & [aceno positivo] & \\
\hline 15 & & & OLHAR [aponta para a tela] & $\begin{array}{c}\text { [gira a cadeira e olha para } \\
\text { a tela] }\end{array}$ & \\
\hline
\end{tabular}

\section{QUADRO 1 - Recurso da Imagem (sala AEE)}

\begin{tabular}{|c|c|c|c|c|c|}
\hline $\mathrm{N}$ & Atividade didática & Tradução & Professor - ações e diálogos & Alunos - ações e diálogos & Contextualização \\
\hline 16 & & & $\begin{array}{l}\text { [olha a tela como se } \\
\text { estivesse procurando onde } \\
\text { clicar] }\end{array}$ & $\begin{array}{l}\text { [olha para a tela e para o } \\
\text { movimento do professor] }\end{array}$ & $\begin{array}{l}\text { Dificuldades do } \\
\text { professor com a } \\
\text { operacionalidade do } \\
\text { LDD. }\end{array}$ \\
\hline 17 & Tradução LS & $\begin{array}{c}\text { LP: Preparação para a leitura } \\
\text { LS: PREPARAR LER }\end{array}$ & $\begin{array}{c}\text { [clica na } 1^{\underline{a}} \text { imagem de } \\
\text { televisão] }\end{array}$ & & $\begin{array}{c}\text { Tradução da frase para } \\
\text { Libras. }\end{array}$ \\
\hline 18 & & & ENTENDER ---?--- & & \\
\hline 19 & & & & ENTENDER ---?--- & \\
\hline 20 & & & $\begin{array}{c}\text { [abre o link da janela } \\
\text { novamente] }\end{array}$ & [aproxima da tela] & $\begin{array}{c}\text { Professor e aluno olham } \\
\text { para a tela. }\end{array}$ \\
\hline 21 & & & & [afasta da tela] & \\
\hline 22 & & & & PREPARAR LER & $\begin{array}{c}\text { Aluno copia a } \\
\text { sinalização da tela. }\end{array}$ \\
\hline 23 & & & $\begin{array}{c}\text { PREPARAR LER ... CERTO - } \\
--!---\end{array}$ & & \\
\hline 24 & & & [clica na $2^{\mathrm{a}}$ janela] & & \\
\hline 25 & & $\begin{array}{c}\text { LP: Esta é a capa do livro } \\
\text { que traz o conto que você vai } \\
\text { ler. }\end{array}$ & & & $\begin{array}{c}\text { Tradução da frase para } \\
\text { Libras. }\end{array}$ \\
\hline
\end{tabular}

(continuação) 


\section{Revista Araticum}

Programa de Pós-graduação em Letras/Estudos Literários da Unimontes v. 21, n.1, 2020. ISSN: 2179-6793

\begin{tabular}{|c|c|c|c|c|c|}
\hline $\mathrm{N}$ & Atividade didática & Tradução & Professor - ações e diálogos & Alunos - ações e diálogos & Contextualização \\
\hline 6 & & $\begin{array}{l}\text { LP: Esta é a capa do livro } \\
\text { que traz o conto que você vai } \\
\text { ler. } \\
\text { LS: CAPA LIVRO TER } \\
\text { CONTAR-FALAR (1) LER (2) }\end{array}$ & $\begin{array}{c}\text { [clica na } 2^{\mathrm{a}} \text { janela] FALAR } \ldots \\
\text { [circula toda a tela] } \\
<\text { QUE }>\text {---?--- }\end{array}$ & & $\begin{array}{l}\text { Professor usa o dedo } \\
\text { indicador para circular } \\
\text { toda a tela do } \\
\text { computador. }\end{array}$ \\
\hline
\end{tabular}

\section{QUADRO 1 - Recurso da Imagem (sala AEE)}

(conclusão)

\begin{tabular}{|c|c|c|c|c|c|}
\hline $\mathrm{N}$ & Atividade didática & Tradução & Professor - ações e diálogos & Alunos - ações e diálogos & Contextualização \\
\hline 28 & & & & LIVRO LER ---?---<dúvida> & \\
\hline 29 & & & $\begin{array}{c}\text { CONHECER PALAVRA } \\
--- \text {--- } \\
\text { [aponta para a palavra } \\
\text { dinheiro] }\end{array}$ & & $\begin{array}{c}\text { Texto em letras } \\
\text { vermelhas, de diferentes } \\
\text { tamanhos, ao lado da } \\
\text { imagem. }\end{array}$ \\
\hline & $\begin{array}{c}\text { Como se fosse dinheiro. } \\
\text { Ilustrações: Mariana } \\
\text { Massarini }\end{array}$ & & & & \\
\hline 30 & & & & $---\tilde{n}---$ & \\
\hline 31 & & & $\begin{array}{c}\text { QUAL ---?--- QUATRO } \\
\text { [aponta para cada palavra do } \\
\text { texto] } \\
\text { CONHECER ---?--- }\end{array}$ & & $\begin{array}{l}\text { Professor mantém o sinal } \\
4 \text { na tela, para dar ênfase } \\
\text { que são } 4 \text { palavras. }\end{array}$ \\
\hline 32 & & & & $---\tilde{n}---$ & \\
\hline 33 & LD Impresso & & [aponta para as palavras no & & Professor interage com o \\
\hline
\end{tabular}




\section{Revista Araticum}

Programa de Pós-graduação em Letras/Estudos Literários da Unimontes v. 21, n.1, 2020. ISSN: 2179-6793

\begin{tabular}{|c|c|c|c|c|c|}
\hline $\mathrm{N}$ & Atividade didática & Tradução & Professor - ações e diálogos & Alunos - ações e diálogos & Contextualização \\
\hline & & & texto escrito/impresso] & [olha o impresso] & impresso \\
\hline 34 & & & $\begin{array}{c}\text { CONHECER }<\text { NENHUM>--- } \\
\text { ?--- }\end{array}$ & & $\begin{array}{l}\text { Professor mantém a } \\
\text { atenção ao impresso }\end{array}$ \\
\hline 35 & & & & $----\tilde{n}---$ & \\
\hline 36 & & & $\begin{array}{c}\text { CONHECER } \\
\text { D-I-N-H-E-I-R-O ---?--- }\end{array}$ & & \\
\hline 37 & & & & $---\tilde{n}---$ & \\
\hline 38 & & & ESPERAR MOSTRAR & & $\begin{array}{l}\text { Professor levanta da } \\
\text { mesa e vai até o armári }\end{array}$ \\
\hline
\end{tabular}

Fonte: Dados da pesquisa. Elaborado pela autora a partir do volume Língua Portuguesa, Coleção Porta Aberta, 5ำ ano, Unidade 3, 2011. p. 49. 


\section{Revista Araticum}

Programa de Pós-graduação em Letras/Estudos Literários da Unimontes v. 21, n.1, 2020. ISSN: $2179-6793$

A compreensão do texto pela ilustração - seguida pelas propostas de respostas orais, tais como "Qual é o título do conto?", "Quem é a autora do conto?", "O que foi ilustrado na capa?" e "Pelo título e pela ilustração da capa, o que você acha que vai acontecer nesse conto?" - promoveu no aluno outras significações. Primeiramente, a simples identificação do animal, ilustrada na Figura 1 e no Quadro 3 (ovelha, linha 4). Diante da imagem que mostra um menino segurando uma correia atada a uma ovelha, ambos com um dos pés elevados, produzindo uma ideia de movimento, o professor, no sentido de provocar o olhar para a imagem, questiona se se trata de levar o animal para passear (linha 11), ao que aluno responde: V-I (linha 12). A seguir, o professor busca a Libras (janela de tradução) para ajudar o aluno na compreensão da atividade. O aluno demonstra inquietação e não entende o que fazer (linhas 15, $19,20,21,27,28,30,32$ e 35). Dentro desse contexto, observa-se que o professor se apoia no material impresso e digital para introduzir as palavras apontando para elas (linhas 26, 29, 31 e 33) e se concentra em uma palavra específica, "dinheiro" (linhas 34 e 36). O aluno continua sem compreender a proposta nem o sentido da imagem para significar-se na atividade.

Para ler a imagem, é preciso compreender em que contexto ela está inserida, uma vez que é compreendida a partir das práticas sociais e culturais nas quais o leitor está presente. O texto contém elementos que estão distantes da realidade do aluno surdo, e esse distanciamento tem origem no processo de aquisição de linguagem, ou seja, nas interações sociais que são fomento para nosso conhecimento de mundo. Carolina Plaza-Pust ${ }^{16}$, Ronice Quadros ${ }^{17}$ e Giselli Maria da Silva e Angélica Guimarães ${ }^{18}$ apontam que as crianças surdas crescem em ambientes onde há predominância de uma língua oral. Devido à condição limitada para a audição e ao desconhecimento da LS por parte de seus familiares, perdem a condição de acessar informações de mundo e suas significações.

De fato, em interações com pais de $\operatorname{surdos}^{19}$, verifica-se que a dificuldade de comunicação destes com os filhos surdos interfere no

\footnotetext{
${ }^{16}$ PLAZA-PUST, 2012, p.950.

${ }^{17}$ QUADROS, 2019, p.34.

${ }^{18}$ SILVA; GUIMARÃES, 2016, p.83.

${ }^{19}$ Interações espontâneas sem cunho investigativo.
} 


\section{Revista Araticum}

Programa de Pós-graduação em Letras/Estudos Literários da Unimontes v. 21, n.1, 2020. ISSN: $2179-6793$

entendimento de tarefas que envolvem transações financeiras. Para esse caso, ao final, quando o professor mostra uma cédula, o aluno demonstra entender 0 objeto como algo que compra, mas não entende o retorno, o troco. Outro fator que vale destacar, apontado pelo professor, é sobre o lanche na escola pública, já que a história se refere ao troco dado no momento de compra do lanche na hora do recreio, na escola. Na escola pública, o lanche é ofertado gratuitamente a todos os alunos, não havendo comercialização ali. Dessa forma, é mais um elemento de distanciamento da representação da "moeda de troca", uma vez que o mercado em ambiente escolar não caracteriza realidade para os alunos. Nesse caso específico, o aluno demonstrou não entender nem supor essa relação comercial.

Para o contexto que envolve uso e apropriação pelo aluno surdo, podese afirmar que a imagem ilustrativa não se alinhou ao texto: o título da história não tem conexão com o que é ilustrado, ou seja, não atende ao propósito, que seria dar conhecimento prévio à leitura, tampouco representa parte da história. $O$ acesso à LS pela tradução da atividade também não auxiliou o aluno surdo na compreensão da tarefa proposta.

Desta forma, na unidade didática aplicada, a composição dos diferentes modos semióticos (imagem, LS e LP) não auxiliaram a compreensão do texto multimodal, dando indícios de que a adaptação não foi elaborada pensando na diversidade de seu público, uma vez que o significado da ilustração não está implicado no contexto e a inserção da LS não promoveu desenvoltura na compreensão da segunda língua.

\section{Considerações finais}

Embora a entrada da tecnologia nos procedimentos educacionais para crianças surdas possa ser vista como um avanço positivo, ainda há que se refletir a aplicabilidade desse recurso. Analisando os dados coletados nessa aplicação de unidade didática de LP adaptado em Libras, constata-se que os aspectos considerados - linguísticos e didáticos ("Preparação para a leitura") confirmam a complexidade do uso e da apropriação por parte do aluno e do 


\section{Revista Araticum}

Programa de Pós-graduação em Letras/Estudos Literários da Unimontes v. 21, n.1, 2020. ISSN: $2179-6793$

professor. Os agentes sociais constroem representações sobre o objeto de ensino e aprendizagem de segunda língua (LD), contudo, quando professores e alunos surdos se deparam com um LD adaptado, não se veem identificados com os modos discursivos apresentados, mesmo que um desses modos referencie sua primeira língua.

Assim confere que, nos LDs investigados, os enunciados das atividades e a forma pela qual se exige uma ação do aluno frente aquele exercício não promove autonomia, não promove compreensão e não promove estímulo, o que pode causar, no aluno surdo, a sensação de incompetência para lidar com a tarefa, mesmo tendo sido solicitada em sua própria língua e excluindo o momento de aprendizagem.

Da maneira com que o LD foi elaborado, a intenção de viabilizar e contemplar as diferenças linguísticas torna-o um produto inacessível e evidencia o desconhecimento no que diz respeito à realidade das comunidades surdas, sobretudo à falta de maior discussão e implementação de métodos pertinentes à condição linguística e à real condição do pleno desenvolvimento do aluno surdo.

\section{Referências}

JOLY, Martine. Introdução à Análise de Imagem. Lisboa, Ed.70, 2006.

KRESS, Gunther; VAN LEEUWEN, Theo. Reading images: the grammar of visual design. New York: Routledge, 2006.

KUNTZE, Marlon; GOLOS, Debbie; ENNS, Charlotte. "Rethinking Literacy: Broadening Opportunities for Visual Learners". In: Sign Language Studies, v. 14, no 2, 2014. p. 203-224.

LEBEDEFF, Tatiana Bolívar. "Aprendendo a ler 'com outros olhos': relatos de oficinas de letramento visual com professores surdos". Cadernos de Educação | FaE/PPGE/UFPel | Pelotas [36]: 175 - 195, maio/agosto 2010.

LEFFA, Vilson José. "Como produzir materiais para o ensino de línguas". In: v. 1, 2008.

Produção de materiais de ensino: prática e teoria. Pelotas: Educat, 2.ed.

MIRANDA, Dayse Garcia. "A multimodalidade no ensino de língua portuguesa como segunda língua para surdos: análise do uso do livro didático adaptado em Libras". Tese de Doutorado. Posling. CEFET-MG, Belo Horizonte, 2019 


\section{Revista Araticum}

Programa de Pós-graduação em Letras/Estudos Literários da Unimontes v. 21, n.1, 2020. ISSN: 2179-6793

PLAZA-PUST, Carolina. "Deaf education and bilingualism". In: PFAU, Roland; STEINBACH, Markus; WOLL, Bencie. (Eds.). Sign Language: An International Handbook. Berlin: De Gruyter Mouton, 2012. p. 949-979

PORTUGUÊS. São Paulo: Editora Moderna, 2005. 1르 ed. 4 volumes. Coleção Pitanguá.

QUADROS, Ronice Muller de. Libras. São Paulo: Parábola Editorial, 2019.

SELVATICI Vera Lúcia de Carvalho Grade. "Gêneros e Letramento Visual: uma proposta para o uso de imagens em atividades de escrita em ILE". In. Gêneros discursivos e multimodalidade: desafios, reflexões e proposta do ensino de Inglês. HEMAIS, Barbara Jane Wilcox. (Org.) Campinas: Ed. Pontes, 2015.

SILVA, Giselli Maria, GUIMARÃES, Angélica Beatriz Castro. "Materiais didáticos para o ensino de português como segunda língua para surdos: uma proposta para o nível básico". In: GONÇALVES, L. (Org.) Português como língua estrangeira, de herança materna: abordagens, contextos e práticas. New Jersey: AOTP/Boavista Press, 2016. p. 79-96

SILVA, Giselli Maria da. "Transitando entre a Libras e o Português na sala de Aula: em busca de estratégias visuais de ensino da leitura". In: Revista X, Curitiba, v. 13, n. 1, 2018. p. 206-229.

SILVA, Renato Caixeta da. "O livro didático de Inglês como um gênero discursivo multimodal promotor de letramentos múltiplos". In: HEMAIS, Barbara Jane Wilcox. (Org.) Gêneros discursivos e multimodalidades: desafios, reflexões e propostas no ensino de Inglês. Campinas: Editora Pontes, 2015.

SILVA, Renato Caixeta da. "Contribuições da visão sociossemiótica da linguagem e da multimodalidade com apoio à educação linguística de surdos". In: MIRANDA, Dayse Garcia e FREITAS, Luciana (Org.) Educação para Surdos: possibilidades e desafios. Belo Horizonte: Mazza Edições, Coleção Pensar a Educação, 2019. p. 61-74.

Dayse Garcia Miranda é graduada em Psicologia Clínica pela FCH-FUMEC; Mestre em Educação pela FaE/UFMG; Doutora em Estudos de Linguagens pelo CEFET-MG. É professora do Departamento de Letras da Universidade Federal de Ouro Preto/MG.

Recebido em17 de fevereiro de 2020. Aprovado em 02 de abril de 2020. 